\title{
MAPPING THE THICKNESS OF QUATERNARY SEDIMENTS IN THE IŠKA ALLUVIAL FAN (CENTRAL SLOVENIA) USING MICROTREMOR METHOD
}

\author{
Lovro RUPAR ${ }^{1)}$ and Andrej GOSAR ${ }^{2), 3)}$ * \\ 1) Kebetova ulica 21, SI-1000 Ljubljana, Slovenia \\ ${ }^{2}$ Slovenian Environment Agency, Seismology Office, Vojkova 1b, SI-1000 Ljubljana, Slovenia \\ ${ }^{3)}$ University of Ljubljana, Faculty of Natural Sciences and Engineering, Aškerčeva 12, SI-1000 Ljubljana, Slovenia \\ *Corresponding author's e-mail: andrej.gosar@gov.si
}

\begin{tabular}{l}
\hline ARTICLE INFO \\
\hline Article history: \\
Received 11 December 2019 \\
Accepted 10 March 2020 \\
Available online 31 March 2020 \\
\hline
\end{tabular}

\section{Keywords:}

Microtremor method

Sediments resonance frequency

Frequency-thickness relationship

Mapping sediment thickness

Iška alluvial fan

Ljubljana Moor

\begin{abstract}
Resonance frequencies of unconsolidated sediments of the Iška alluvial fan (Ljubljana Moor basin) were derived using microtremor method. Free-field measurements were conducted in a grid with point spacing of approximately $250 \mathrm{~m}$. The sediments frequency-thickness relationship, $h=202.97 f^{-1.139}$, was obtained on the basis of 107 microtremor measurements, six existing boreholes that reached the Pre-Quaternary basement and two seismic reflection profiles. The reliance of the obtained relationship was evaluated with the $\mathrm{R}^{2}$ coefficient, which shows a very good level of determination. The resonance frequency map reveals the existence of an N-S oriented deeper buried valley (maximum depth $119 \mathrm{~m}$ ) in the Western part of the alluvial fan. The microtremor HVSR amplitude map does not show any specific spatial distribution pattern, with the exception of a relatively narrow band of low amplitudes located north of Iška vas. This is probably related to an area of severely fractured bedrock along the Mišji Dol fault. Map of the Quaternary sediment thickness and map of the Pre-Quaternary basement topography were constructed on the basis of the established relationship. The basement topography map shows rather steep western slopes of the buried valley down to deepest part, followed by a gradually ascending basement towards the Eastern part of the fan. The comparison of the obtained parameters $a$ and $b$ in frequency-thickness relationship with other sedimentary basins around the world reveals a small variation of $b$ values, and a rather large range of $a$ values, which implies that the parameter $a$ is characteristic for certain geological areas. The results of this research will find use in constructing more accurate hydrogeological models and for assessment of possible sediments-structure resonance effects in seismic microzonation.
\end{abstract}

\section{INTRODUCTION}

The Iška alluvial fan is located in the Southern part of the Ljubljana Moor basin (Central Slovenia), at the foot of Krim-Mokerc hills. It lies between the villages of Staje, Tomišelj, Vrbljene, Strahomer and Iška vas (Figs. 1 and 2), and is about $6 \mathrm{~km}^{2}$ large. Because of its importance for drinking water exploitation, it is relatively well explored with boreholes and geophysical profiles. Most notable previous research includes the application of microtremors method to determine the frequencythickness relationship for the whole Ljubljana Moor basin (Gosar and Lenart, 2010). This was followed by a pilot project of the Geological Survey of Slovenia in which a geological database system was established and a hydrogeological map with the scale 1: 25.000 was constructed (Lapanje et al., 2014). Lastly, the area was examined with high resolution seismic reflection profiling (Mencin, 2015).

Due to the point or linear nature of existing borehole and geophysical data, a supplementary method for obtaining the 3D model of the Pre-
Quaternary basement that would better cover the whole area of the Iška alluvial fan was necessary. Therefore, we applied the microtremor method (MHVSR method) in a grid with point spacing of approximately $250 \mathrm{~m}$ to assess the morphological characteristics of the subsurface. The method has been extensively used in previous decades for determining the resonance frequency of unconsolidated sediments for seismic microzoning and, with the use of inverse modelling, for determining subsurface shear-wave velocity depth structure (Molnar et al., 2018). Because the sediments frequency-thickness relationship shows stability in the majority of sedimentary basins, the MHVSR method has been together with complementary borehole or geophysical data, also used for mapping the sediments thickness (Ibs-von Seht and Wohlenberg, 1999). The main condition for its effective use is a sufficient impedance contrast between unconsolidated sediments and the bedrock (Lermo and Chavez-Garcia, 1994). However, lateral heterogeneity and 3D subsurface effects can hinder its effectiveness (Guéguen et al., 2007; Le Roux et al., 


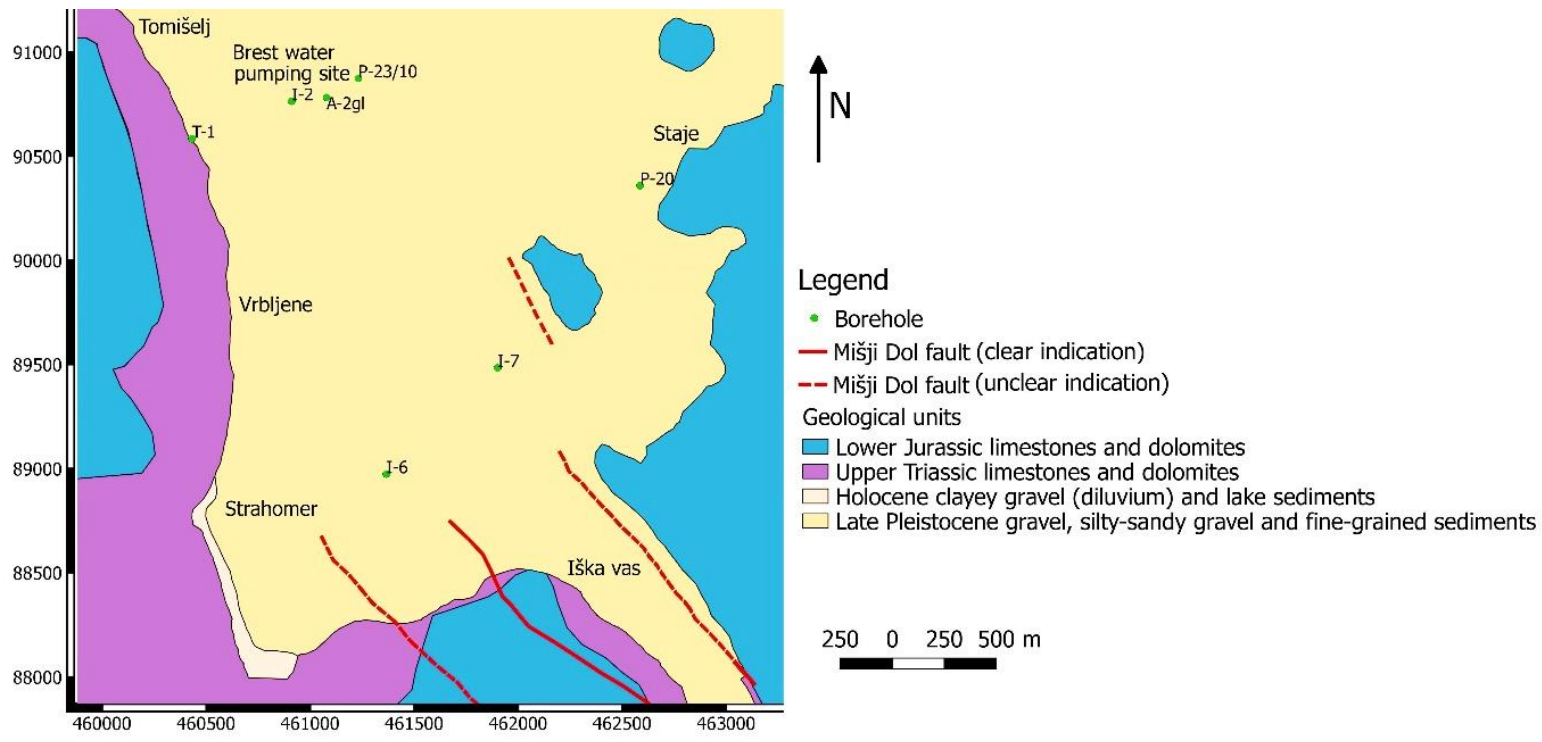

Fig. 1 Geological map of Iška alluvial fan area (modified from Lapanje et al., 2014).

2012). The main advantage of this method is its low cost and the determination of sediments resonance frequency without knowing the thickness of sediments and their vertical $S$-wave velocity profile (Delgado et al., 2000b).

First, isofrequency and isoamplitude HVSR maps were made based on 107 microtremor measurements. Based on the obtained frequency data set, previously conducted seismic reflection profiles and the depths obtained from existing boreholes, we established the relationship between the sediment's resonance frequency and their thickness. Because we aimed to explore the subsurface topography, this resulted in the construction of maps that represent Quaternary sediment thickness and the PreQuaternary bedrock topography. Since several studies of sediments frequency-thickness relationship for various sedimentary basins across the world were carried out, a comparison of the parameters $a$ and $b$ was also conducted to complement the findings in this research.

\section{GEOLOGICAL SETTING}

The Iška alluvial fan is surrounded by Mesozoic carbonates, which also represent the bedrock (Fig. 1). Quaternary unconsolidated sediments are divided into several units. The upmost NW part of the alluvial fan, between Tomišelj and Brest, consists of interchanging Pleistocene gravel and fine-grained sediments. These sediments are in contact with Pleistocene silty-sandy gravel. Gravel and silty-sandy gravel, mostly consists of carbonate pebbles, and covers the whole $S$ and SE part of the alluvial fan. Horvat et al. (2013) determined the age of the sediments on the basis of borehole P-23/10, which showed that the sediments have been deposited in the last 45000 years. This was estimated on the basis of dating the sediments at two different levels. The sediments at depth $2 \mathrm{~m}$ were dated as being about 16000 years old and the sediments at depth of $85 \mathrm{~m}$ as being approximately 40000 years old. Marsh sediments, represented by silty clay and peat (late Pleistocene and Holocene), are visible $\mathrm{N}$ of the Iška alluvial fan. A couple of meters of clayey gravel (Holocene) has deposited at the foothills of surrounding mountains. Thin layer of lake sediments (silt and clay, Holocene) has deposited S of Strahomer (Lapanje et al., 2014). A dextral strike slip Mišji Dol fault (Buser, 1969) crosses the area. In its $\mathrm{N}$ part, the main fault line divides into two separate branches, of which the $\mathrm{W}$ branch crosses the $\mathrm{S}$ part of the Iška alluvial fan (Lapanje et al., 2014).

\section{METHODOLOGY}

Microtremor method (MHVSR - Microtremor Horizontal to Vertical Spectral Ratio) is a technique that calculates the ratio of the horizontal to vertical Fourier (amplitude) spectra derived from microtremors recorded by a three-component sensor (Molnar et al., 2018). There is empirical evidence that the maximum or the peak in the MHVSR spectral ratio appears at the frequency, which equals the resonant frequency of sediments at a certain site (Field and Jacob, 1993; Lachet and Bard, 1994).

When sufficient number of data about the depth of a sedimentary basin (boreholes, vertical electrical soundings or seismic refraction and reflection surveys) is given, a direct relationship between the resonance frequency $(f)$ and the thickness $(h)$ of sediments

$h=\mathrm{a} f^{\mathrm{b}}$

can be established. Using this relationship, the microtremor method can then be used as an exploration tool for mapping the thickness of sediments (Ibs-von Seht and Wohlenberg, 1999). In this procedure it is important, that the depth range of input data extends over the full range of depths we intend to map later with microtremors (Gosar and Lenart, 2010). 


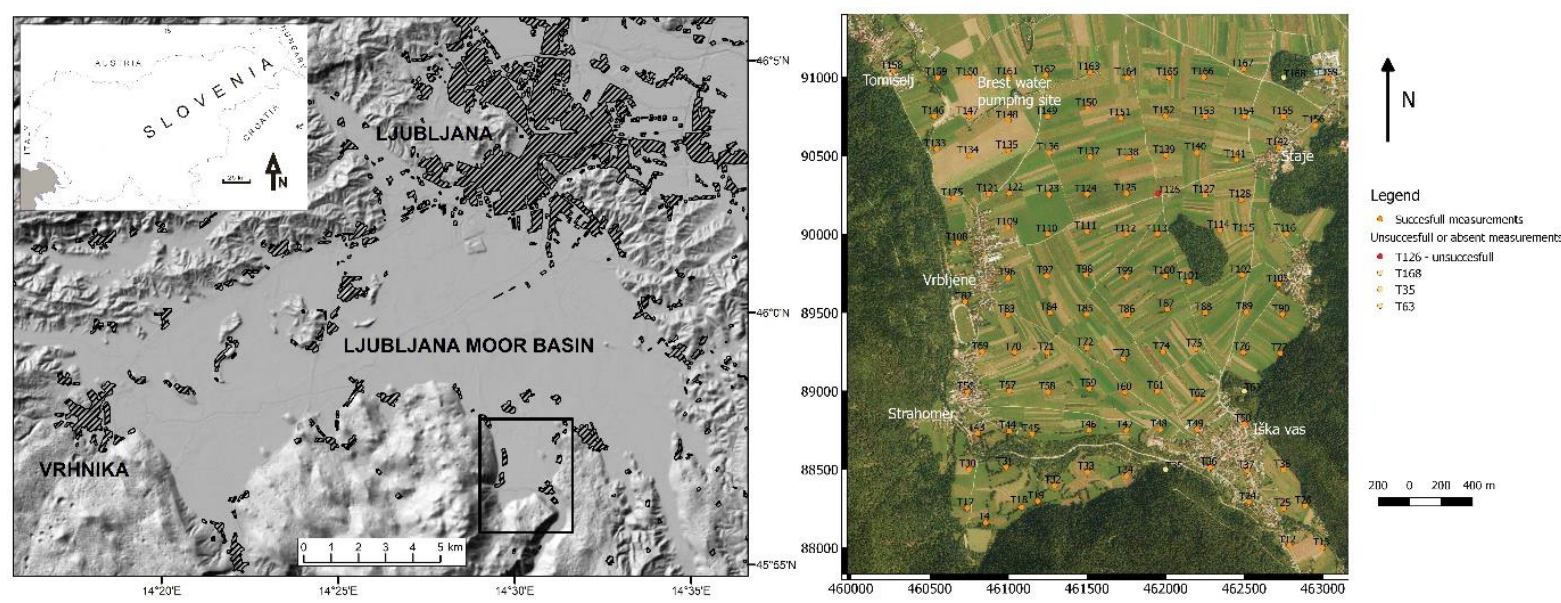

Fig. 2 Locations of measurements.

The obtained MHVSR curves carry information about the main characteristics of the subsurface, such as lateral heterogeneity of sediments composition and velocity reversals (Bonnefoy-Claudet et al., 2008; Castellaro and Mulargia, 2009; Uebayashi et al., 2012; Macau et al., 2015).

\section{MICROTREMOR MEASUREMENTS AND RESULTS OF MHVSR ANALYSIS}

Free-field microtremor measurements (Fig. 2) were carried out on an approximately $6 \mathrm{~km}^{2}$ large area of the Iška alluvial fan, in a grid with point spacing of approximately $250 \mathrm{~m}$, only in stable weather conditions (wind speed below $5 \mathrm{~m} / \mathrm{s}$, absence of rain). The deviation from a regular grid is a consequence of inappropriate conditions at some points (crops, farm fields).

The total number of measurements was 108, of which only one (T126) was unsuccessful and was excluded from further analyses. Microtremor measurements were performed with a portable Tromino seismograph (Moho, 2018), which has all the electronic components integrated in a single case. The total absence of external cables enables the measurement of a virtually unperturbed wave field. Three channels connected to three orthogonal electrodynamic velocimeters with the saturation levels being set to full scale $(51 \mathrm{mV})$ were used for acquisition. Prior to the seismograph being placed on the ground, a levelled $15 \times 20 \mathrm{~cm}$ spot was prepared. The first few centimetres of topsoil, alongside stones, cobbles and other surficial dirt was removed. The seismograph was then placed on the ground, with the main axis oriented in the N-S direction. By alternatively pressing on the lowermost corners of the box and on the middle of the top edge, the seismograph was set in a horizontal position. Good coupling between ground and seismograph was obtained with the three long spikes mounted at the base of the seismograph. We avoided taking measurements in the vicinity of sources of monochromatic noise and near roads in order to minimize transient noise influence.
The sampling frequency was $128 \mathrm{~Hz}$ and the recording length $20 \mathrm{~min}$. These are the recommended values for spectral analysis down to $0.5 \mathrm{~Hz}$ (SESAME, 2004). The recommended duration of a single measurement was not met only in two cases (T56 and T108), but the results were later proved to fulfil SESAME (2004) criteria for MHVSR curve stability and clarity and were therefore included in further analyses.

The MHVSR analysis was performed in the following way. The recorded time series of two horizontal (N-S and E-W) and the vertical (up-down) components were visually inspected to identify erroneous measurements, stronger transient noises or the presence of monochromatic noise throughout the entire recording. Each recording was then split into non-overlapping $30 \mathrm{~s}$ long windows. Through the use of Fourier transformation, the amplitude spectra, in the range of 0.1-64 Hz was computed for all windows of an individual component. The Fourier spectrum was then smoothed using triangular window with $5 \%$ smoothing. The correction for the sensor transfers function was also made. Then the spectral ratio for each time window was computed as the ratio between the geometric average of both horizontal components $\left(\mathrm{H}_{\mathrm{N}-\mathrm{S}}\right.$ in $\left.\mathrm{H}_{\mathrm{E}-\mathrm{w}}\right)$ and the vertical component $(\mathrm{V})$

$\frac{\sqrt{\mathbf{H}_{\mathrm{N}-\mathrm{S}} \times \mathbf{H}_{\mathrm{E}-\mathrm{W}}}}{\mathrm{V}}$

From the colour-coded plot of spectral ratios for all windows (Fig. 3 right), the windows including strong transient noise were identified in order to be excluded from further computation. At the end, the average HVSR function with a $95 \%$ confidence interval was computed (Fig. 3 left).

Those peaks that are of stratigraphic origin exhibit an eye shape or a deviation of the vertical amplitude spectre from both of the horizontal components (Fig. 4, T122 right). When evaluating the obtained MHVSR curves and peak frequencies, SESAME (2004) criteria for curve stability and clarity were used. Satisfying the curve stability criteria, 

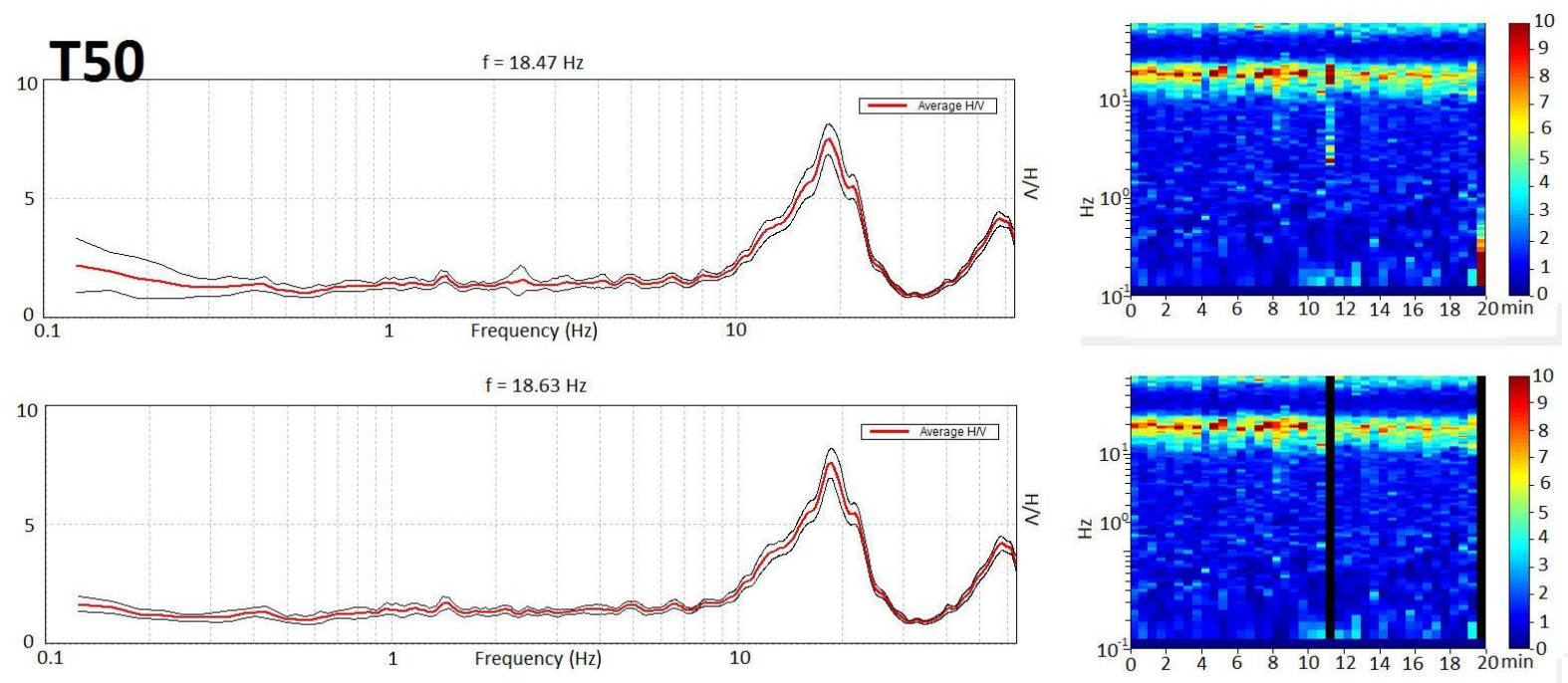

Fig. 3 Average MHVSR curve (left), before and after the elimination of time windows (colour-coded plot-right) that exhibit stronger noise influence for measuring point T50.

which are based on the relation of the peak frequency to the window length, the number of significant cycles and the standard deviation of the peak amplitude, implies that the obtained MHVSR curve is representative and that a repeated measurement on the same location or a different, but sensible, time window selection, would yield the same results. The six criteria for a clear HVSR peak are based on the relation between MHVSR curve peak amplitude and its values elsewhere on the curve, and on the standard deviations of the peak frequency and amplitude. If a sufficient number of criteria are met (all three for stability and at least five for a clear peak), the frequency of the peak is considered to be the fundamental frequency of the sediments down to the first strong impedance contrast (SESAME, 2004). In some cases where at least five criteria for a clear peak were not fulfilled (Fig. 4, T115 and T154) it was still possible to derive the sediment frequency with the study of the MHVSR curve peak amplitude and by examining the Fourier (amplitude) spectra. Additionally, peak frequencies were compared to those of the surrounding measurements (Stanko et al., 2019). The main reasons for the failure of the above criteria were a high level of lowfrequency noise disturbances during the whole $20 \mathrm{~min}$ of acquisition or the presence of several peaks in the spectrum.

Selected examples of MHVSR graphs are shown in Figure 4. Clear peaks were obtained in the majority of the measurements, with peak frequencies ranging from $1.59 \mathrm{~Hz}$ to $18.63 \mathrm{~Hz}$. In a large number of cases there is a sharp, rather symmetrical peak in the MHVSR curve that has a relatively large amplitude (larger than 5) and a narrow $95 \%$ confidence interval (Fig. 4, T122 left, T17). In this instance we can, with great certainty, derive the sediments resonant frequency. In some cases additional side peaks with smaller amplitudes are present. This is mostly due to anthropogenic influence (transients, industry), but sometimes it may indicate a shallower layer with great impedance contrast (Delgado et al., 2000b; Haghshenas et al., 2008).

In the case where two peaks (Fig. 4, T44, T70), both satisfying the criteria for a clear peak, were obtained, the amplitude spectra were examined to determine whether one of the peaks is of anthropogenic origin (Fig. 4, T44). Sometimes this was not possible, because both peaks were of stratigraphic origin. Castellaro et al. (2005) showed this when mapping landslide bodies. They can be attributed to the presence of two impedance contrasts (greater than 4) at different depths (SESAME, 2004). In such cases the peak with the larger amplitude was selected, or, when both of the amplitudes were very similar, the one with the lower frequency was selected (Fig. 4, T70).

Those peaks on the MHVSR curve that are of anthropogenic origin exhibit spurious peaks on the amplitude spectra (Fig. 4, T44 right, T36 right, T57 right and T126 right) of all three components (N-S, E$\mathrm{W}$ and vertical). Furthermore, lowering the smoothing level causes the anthropogenic peaks to become sharper and thinner, whereas stratigraphic peaks stay undeterred. In the case of T57 the measurement was dominated by a prominent low-frequency noise, which is reflected in high amplitudes in the $\mathrm{H} / \mathrm{V}$ spectral ratio at frequencies below $1 \mathrm{~Hz}$ (Fig. 4, T57 left). While at points T57, T44 and T36 distinguishing the peaks was simple, with the resonant frequencies being $2.09 \mathrm{~Hz}$, $1.75 \mathrm{~Hz}$ and $4.5 \mathrm{~Hz}$, this was not the case for T126 (Fig. 4, T126 left). Although the measurement was repeated, the peak frequency could not be obtained. We think this has to do with the combination of consistent low-level noise throughout the duration of the measurement and a possible poor ground coupling due to inadequate soil conditions. 

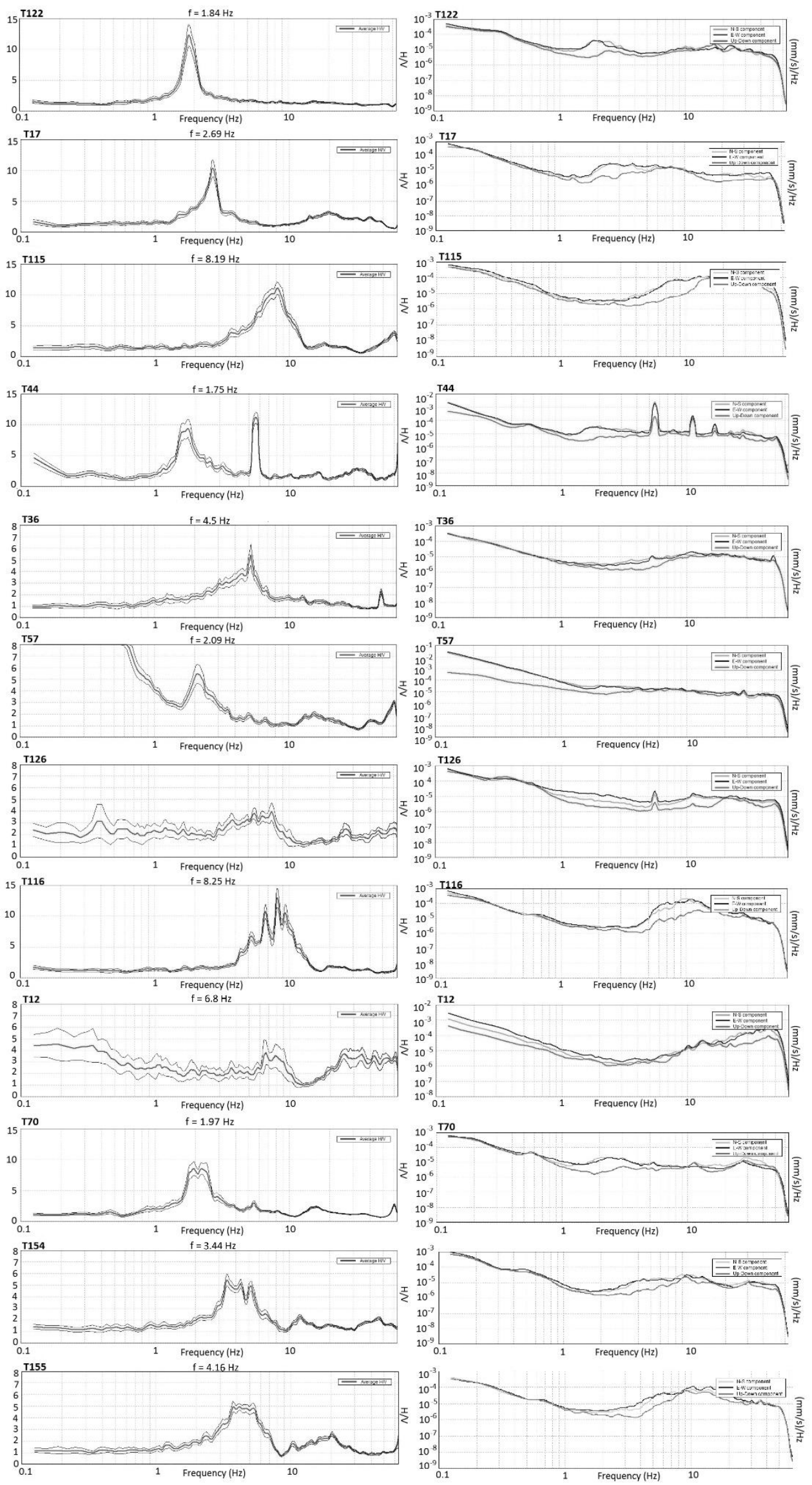

Fig. 4 Selected examples of MHVSR curves and amplitude spectra. The scale is different at some sites, due to higher amplitudes. Thin lines represent a $95 \%$ confidence interval. Locations of measurements are shown in Figure 2. 


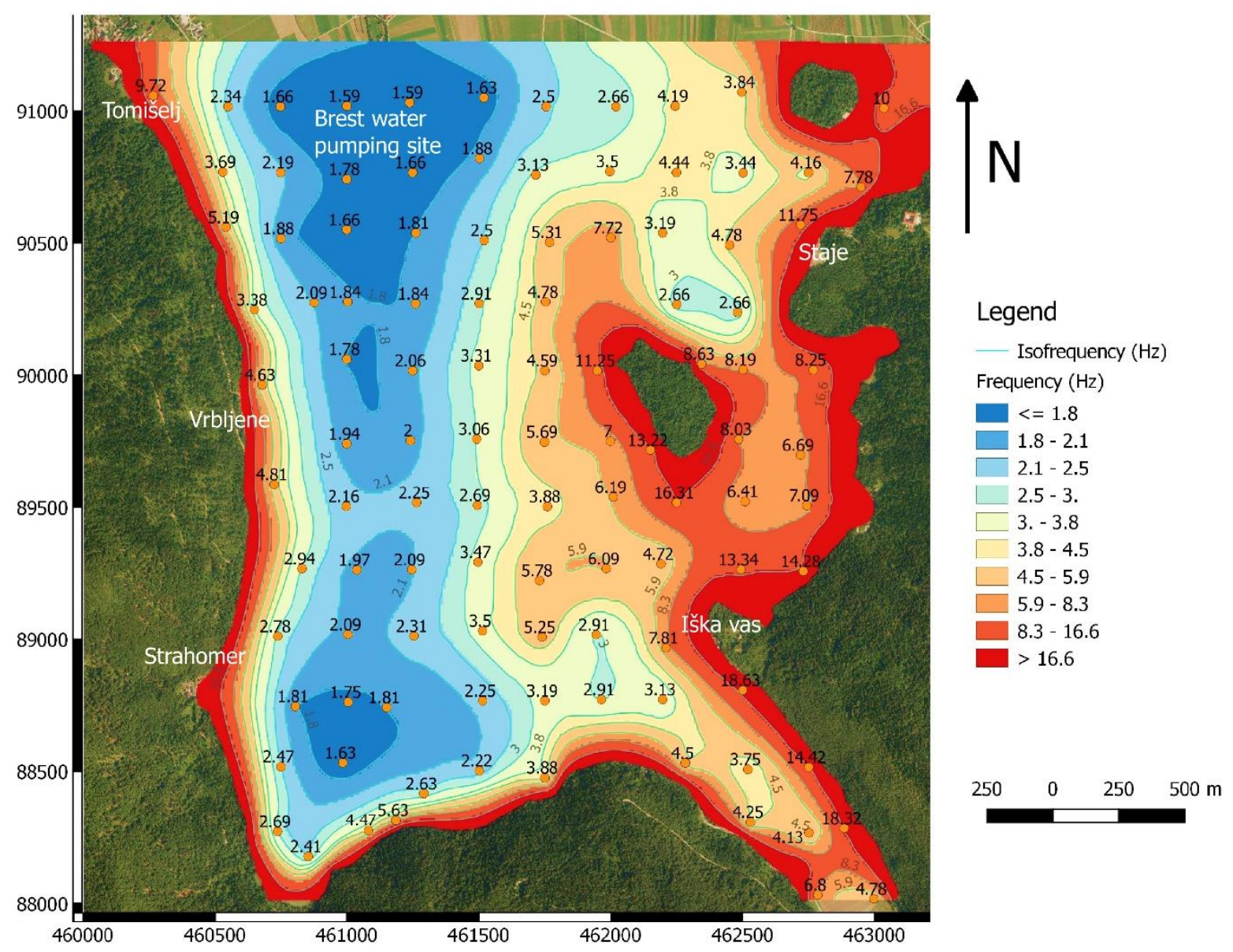

Fig. 5 Isofrequency map of sediments resonance frequency.

In some cases, the MHVSR curve exhibited several peaks (Fig. 4, T116) or a broad peak (Fig. 4, T155). In theory a broad peak shows the existence of a tilted boundary between softer and stiffer layers or the presence of lateral heterogeneities that lead to 2D or 3D effects. The frequency was chosen by comparing the adjacent points, examining the amplitude spectra, and the amplitudes of smaller peaks visible in the broad peak frequency range. In the case of multiple peaks, the one with the largest amplitude was chosen.

The curve at measurement point T12 (Fig. 4, T12 left) exhibits a relatively wide $95 \%$ confidence in the whole spectral ratio and reflects monochromatic and transient noise influence in a wide range of frequencies. The stability of the spectral ratio was therefore lower and, because the noise was persistent during the whole $20 \mathrm{~min}$ record, it was not possible to improve the signal-to-noise ratio by eliminating certain time windows. Another possible explanation for a wider $95 \%$ confidence interval is the location of the measuring point at the edge of the sedimentary basin. After examining the amplitude spectra of all the components (Fig. 4, T12 right), the peak at $\mathrm{f}=6.8 \mathrm{~Hz}$ was determined to be the one that reflects the impedance contrast between the Quaternary sediments and the Pre-Quaternary basement.
Although HVSR amplitude reflects impedance contrast, it cannot be used in MHVSR method for its quantitative assessment, since many factors could have influence on amplitude. Therefore, it is mainly used qualitatively to compare different areas.

\section{MAPS OF SEDIMENTS RESONANCE FREQUENCY AND HVSR PEAK AMPLITUDES}

With the exception of T126, all points (107) were used for the construction of the isofrequency map (Fig. 5). Point data were interpolated with universal spherical kriging by a program written in Python using the PyKrige library.

The highest frequencies ( $\mathrm{f}>16.6 \mathrm{~Hz}$ ) are limited to the boundaries of the sedimentary basin and the surroundings of two carbonate monoliths in the alluvial fan area. The lowest measured frequencies ( $f<1.8 \mathrm{~Hz}$ ) appear in the vicinity of the Brest water pumping site and in the SW part, near Strahomer. Spatial distribution of resonance frequencies shows gradual lowering towards the $\mathrm{W}$. There is a relatively wide belt of low frequencies ( $\mathrm{f}<3 \mathrm{~Hz}$ ) stretching from $\mathrm{N}$ to $\mathrm{S}$ in the Western part of the alluvial fan, that implies the existence of a rather symmetrical buried valley.

Most of the HVSR peak amplitudes fall in the range between 4 and 9 . No measurement has 


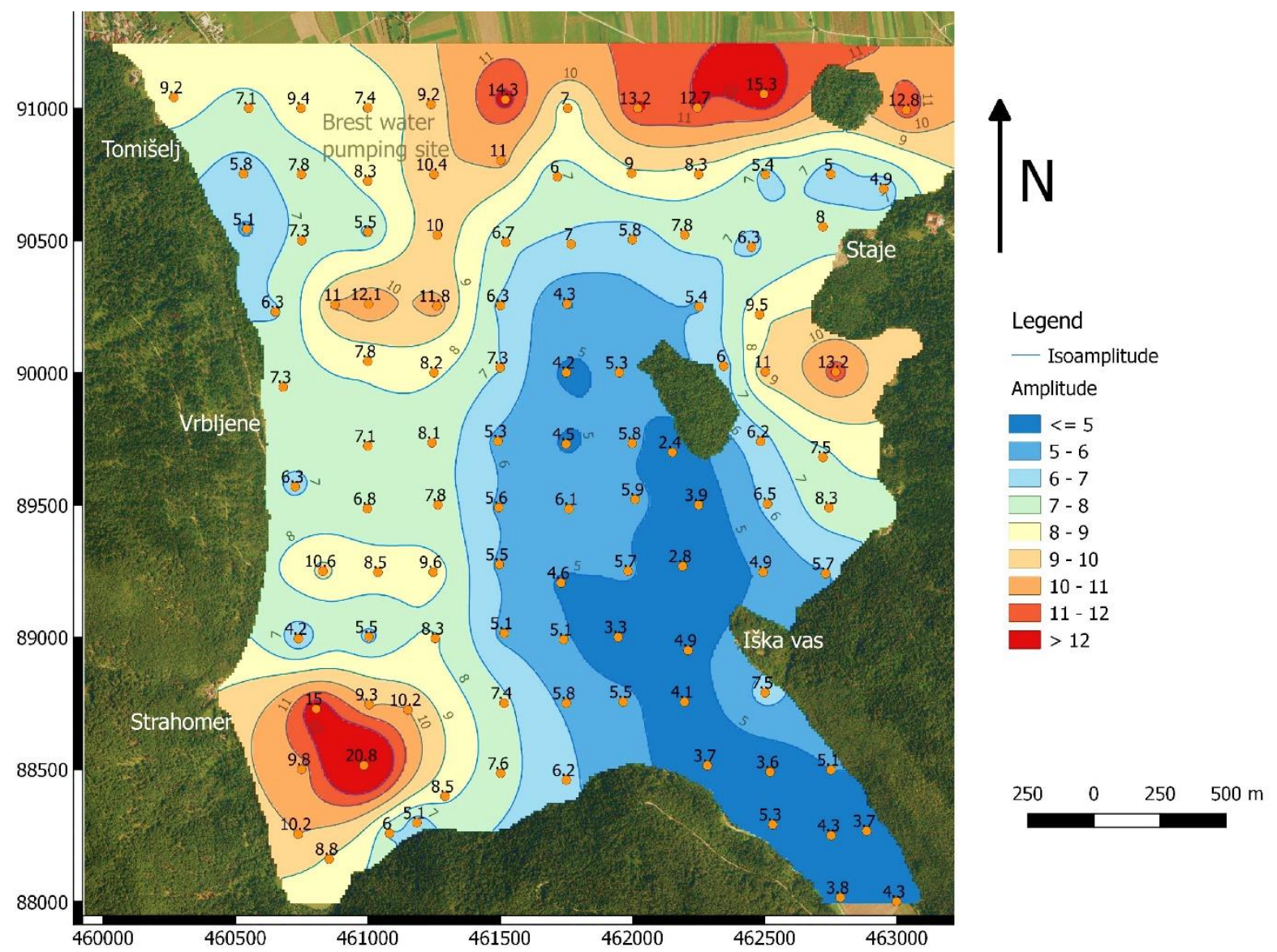

Fig.6 Map of MHVSR peak amplitudes.

the amplitude lower than 2, which would indicate that the local subsurface does not exhibit any sharp impedance contrast. With the amplitude being an indicator of the impedance contrast between unconsolidated sediments and the bedrock, we can use these values as a rough estimate of the lower bound of seismic ground amplification. According to SESAME (2004) there is around $80 \%$ chance that the actual site amplification for the Fourier spectra around the resonance frequency is larger than the $\mathrm{H} / \mathrm{V}$ amplitude.

All points (107) were used for the construction of the MHVSR peak amplitude map (Fig. 6) and point data interpolated with ordinary power kriging by a program written in Python using the PyKrige library. A different kriging method was used due to a better level of agreement with the measured amplitudes in comparison with other variogram models.

The highest amplitudes (values over 12) are limited to the $\mathrm{N}$ part of the Iška alluvial fan, $\mathrm{S}$ of Staje and in the vicinity of Strahomer. Spatial distribution of amplitudes lower than 5 reveals a relatively wide belt in the $S$ part of the fan, stretching across Iška vas towards the N. This could be related to an area of severely fractured bedrock due to Mišji Dol fault, which results in a lower impedance contrast with unconsolidated sediments.

\section{FREQUENCY-THICKNESS RELATIONSHIP AND MAPS OF QUATERNARY SEDIMENT THICKNESS AND BASEMENT TOPOGRAPHY}

The frequency-thickness relationship was derived from the resonance frequency map and the results of previous geophysical investigations and boreholes data. Altogether, there were 1550 data with known depth to the bedrock available. Two seismic reflection profiles, HRS1 with geophone spacing of $2 \mathrm{~m}$, and HRS2 with geophone spacing of $3 \mathrm{~m}$ (Mencin, 2015) contributed 1544 data points, while the remaining six were attributed to boreholes. The uncertainty of thickness values obtained from seismic reflection profiles was evaluated with a $10 \%$ error. Uncertainty of such measurements could be related to unrecognized vertical or horizontal velocity variations that can cause distortions on the seismic section, and the use of less accurate velocities for time to depth transformation (Gosar and Ravnik, 2007).

After eliminating strongly outlying values, there was a total of 1407 data points available for calculating the sediments frequency-thickness relationship, 1401 data from seismic reflection and 6 boreholes. Because the determination of sediment thickness for both of these methods is erroneous to a certain level, we constructed multiple weighted models. Power function (equation 1) was used for curve fitting. The relation that best describes the obtained data is 

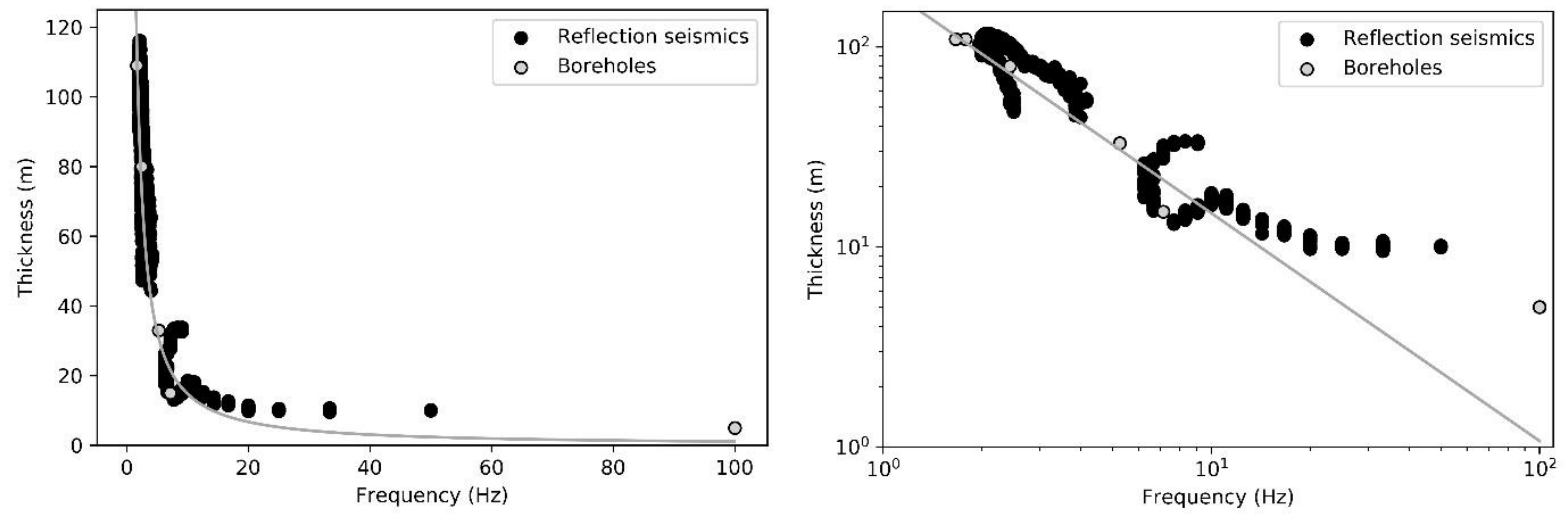

Fig. 7 Frequency-thickness relation for the Iška alluvial fan $\left(h=202.97 f^{-1.139}\right)$. Left - linear scale, right - log-log scale.

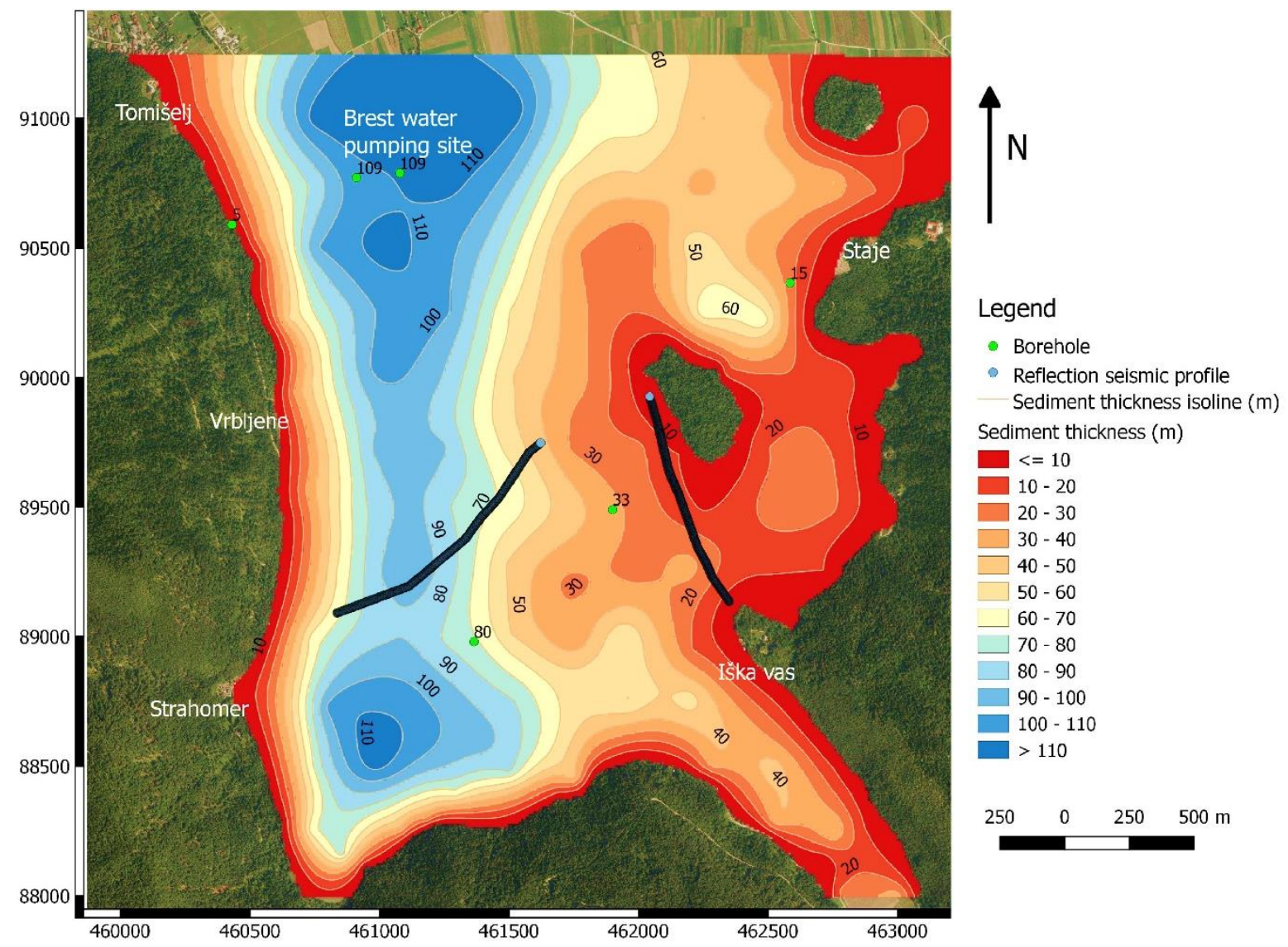

Fig. 8 Map of Quaternary sediment thickness, with boreholes and seismic reflection profiles.

$$
h=202.97 f^{-1.139}
$$

with the $\mathrm{R}^{2}$ value being 0.929 , which means a good level of determination (Fig. 7).

As is apparent from Figure 7, the data matches well with the derived curve for frequencies below $25 \mathrm{~Hz}$. For larger frequencies it is relatively worse, but only few data point was available there. One possible reason for a worse correlation between data and the curve in this frequency range is the fact that such frequencies occur at the edges of the sedimentary basin where 2D and 3D effects that increase the uncertainty of the results are present. Although less reliable, they were still taken into account, when computing the frequency-thickness relationship.

The map of Quaternary sediment thickness (Fig. 8) was constructed on the basis of established frequency-thickness relationship (equation 3). We calculated sediment thicknesses on all microtremor measurement points and then interpolated the obtained values with universal spherical kriging. 


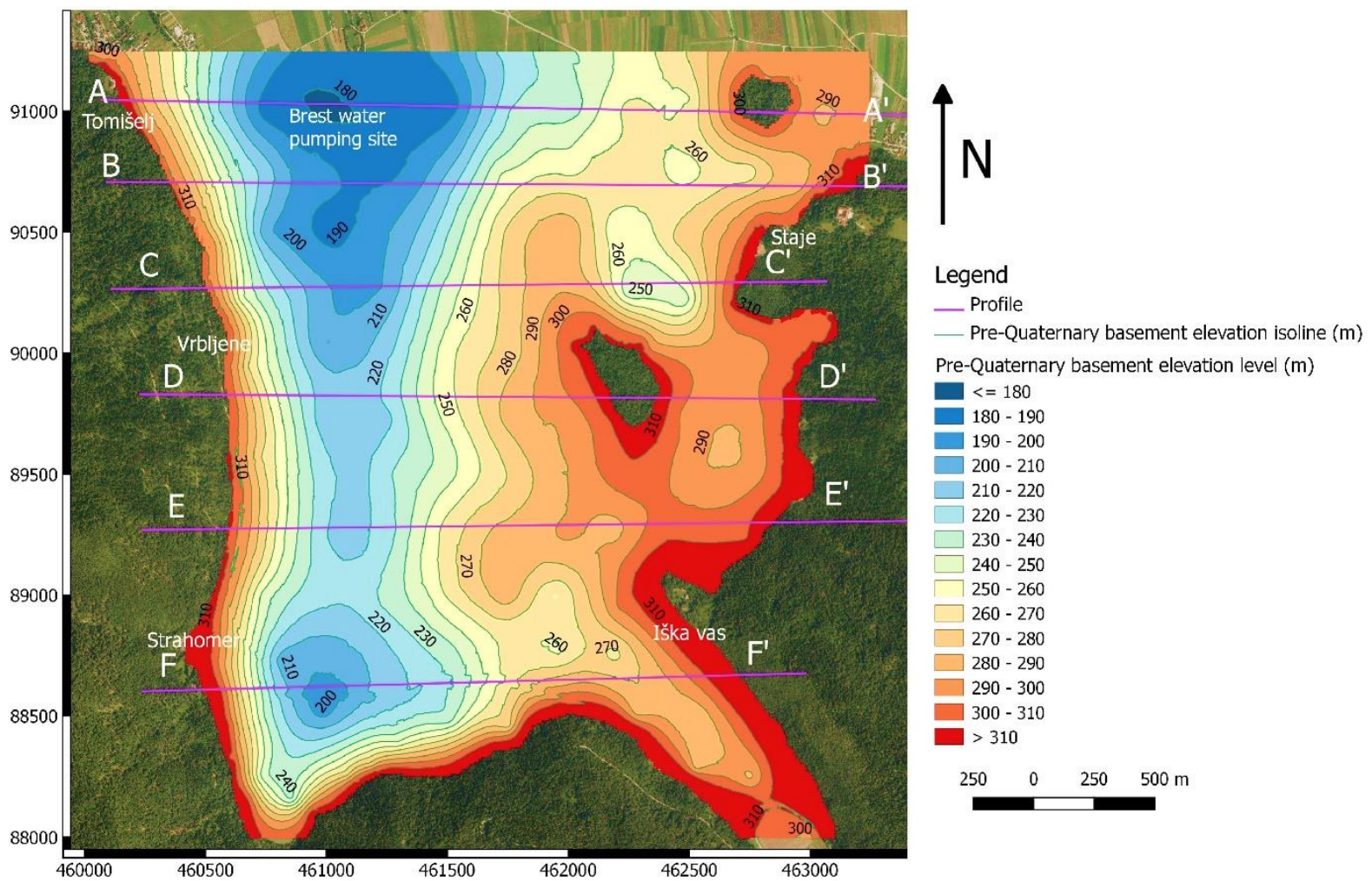

Fig. 9 Map of the Pre-Quaternary basement topography, with locations of profiles shown in Figure 10.

The map shows a gradual increase of sediment thickness from $\mathrm{E}$ to W. A deeper buried valley stretching from $\mathrm{N}$ to $\mathrm{S}$ is present in the $\mathrm{W}$ part of the Iška alluvial fan. In this relatively wide area sediment thickness is over $90 \mathrm{~m}$, with the maximum depth reaching $119 \mathrm{~m}$. The thickest sediment layers (over $110 \mathrm{~m}$ ), are present near the Brest water pumping site and in the vicinity of Strahomer. As expected from the processed data the thinnest layers are located in the outskirts of the alluvial fan, in areas closest to outcropping bedrock. Thinner sediments are generally found in the Eastern part, where their thickness rarely reaches $50 \mathrm{~m}$. Several smaller depressions are found across the whole Iška alluvial fan, but sediments thickness inside them doesn't exceed its surroundings very much.

Comparison between the constructed map and borehole data shows a relatively high level of agreement. The largest deviation in sediment thickness is seen at boreholes with bedrock depth at $5 \mathrm{~m}$ and $15 \mathrm{~m}$ (more than $50 \%$ ). These two boreholes lie near the outcropping bedrock, meaning that $2 \mathrm{D}$ and $3 \mathrm{D}$ effects influence the microtremors results. In the case of remaining boreholes the deviations are much smaller. The deviation of sediment thickness and the depth obtained with drilling is about $10 \%$ for the borehole reaching $80 \mathrm{~m}$, and even less in the case of boreholes that reached $33 \mathrm{~m}$ and $109 \mathrm{~m}$, where the deviation is less than $5 \%$.

The average surface elevation of Iška alluvial fan is $309 \mathrm{~m}$. The highest elevation is at the SE part of the area, where it reaches $332 \mathrm{~m}$, and then it gradually decreases towards the NW, where it reaches $295 \mathrm{~m}$. The map of the Pre-Quaternary basement topography (Fig. 9) was constructed by subtracting sediment thickness from the 1-m resolution digital elevation model obtained with LiDAR scanning (ARSO, 2015). The map shows several shallow depressions E of the buried valley. The lowest elevation level is located in the area of Brest water pumping site. The buried valley is characterized by a steeper W slope, followed by a gentler E slope.

The subsurface morphology is shown on six parallel profiles (Fig. 10) from $\mathrm{N}$ to $\mathrm{S}$, and on which previously described bedrock morphological characteristics are all visible.

\section{COMPARISON OF THE OBTAINED FREQUENCY THICKNESS RELATIONSHIP WITH THE ENTIRE LJUBLJANA MOOR BASIN AND WITH OTHER SEDIMENTARY BASINS IN THE WORLD}

The comparison between previously obtained frequency-thickness relationship for the entire Ljubljana Moor basin (Gosar and Lenart, 2010) $h=105.53 f^{1.250}$ with the one obtained in this study (eq. 3, Fig. 11) reveals a rather large difference between the obtained parameter $a$ and a relatively good agreement in parameter $b$. Relatively large deviation could imply that parameter $a$ is characteristic for a certain sedimentary basin or a region inside a sedimentary basin. The deviation of parameter $a$ reflects the differences in shear wave velocity for the Iška alluvial fan and the rest of the Ljubljana Moor basin, which are expected due to 


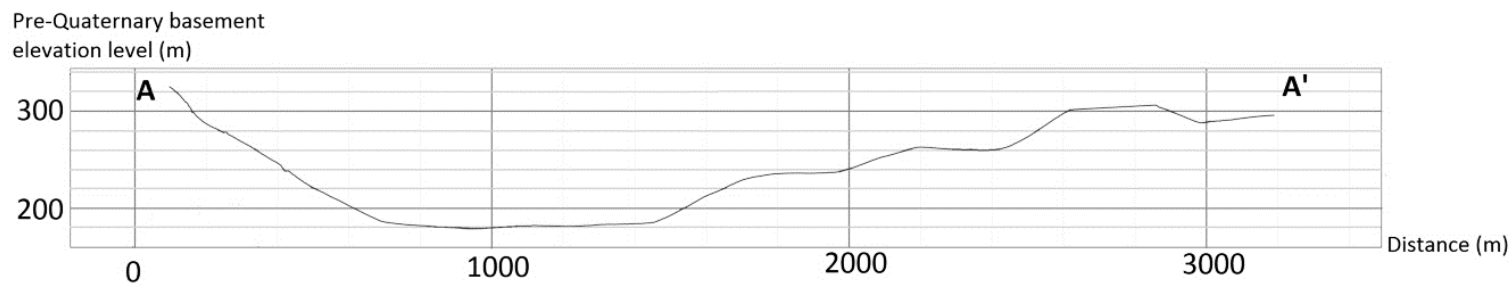

Pre-Quaternary basement

elevation level $(\mathrm{m})$

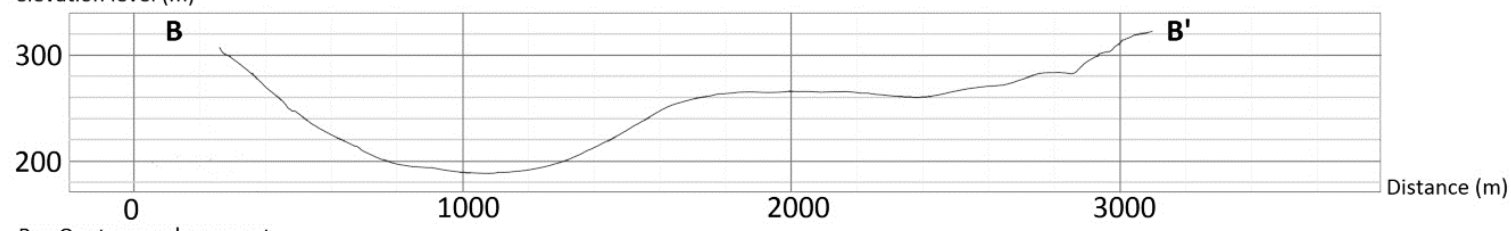

Pre-Quaternary basement

elevation level $(\mathrm{m})$

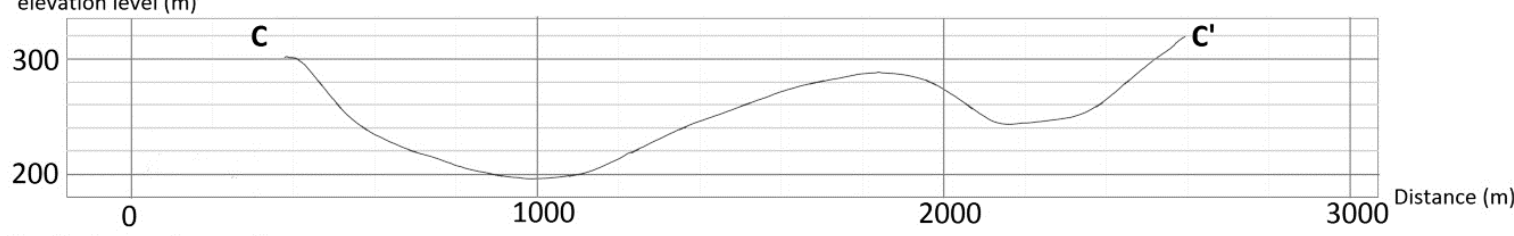

Pre-Quaternary basement

elevation level $(\mathrm{m})$

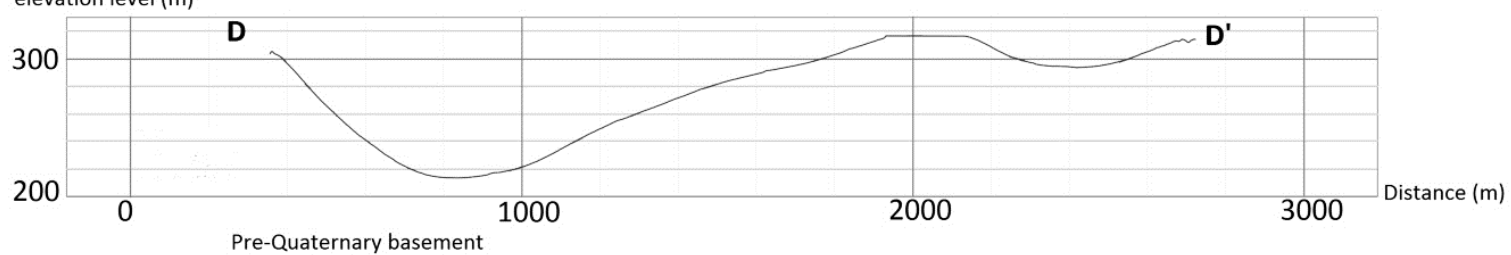

elevation level (m)

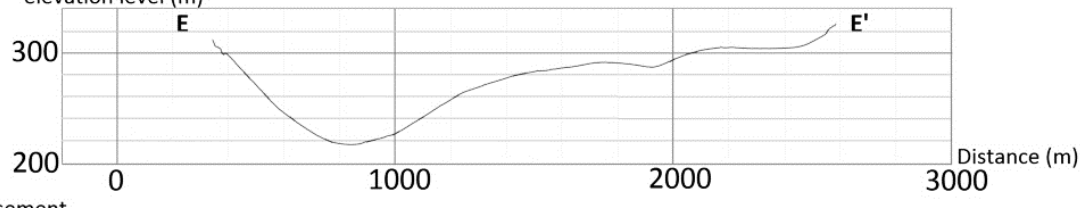

Pre-Quaternary basement

elevation level $(\mathrm{m})$

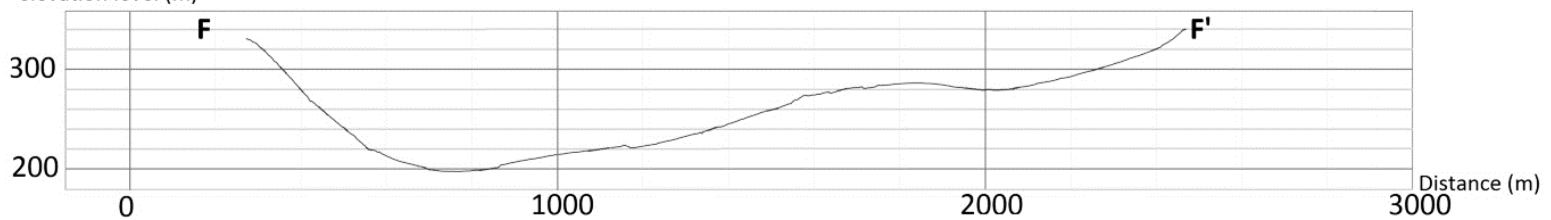

Fig. 10 Six parallel profiles from $\mathrm{N}$ to $\mathrm{S}$ showing the main bedrock morphological characteristics.

differences in sedimentological characteristics of sediments that comprise these two areas. Shear wave velocity increases with the increasing lithostatic pressure and the level of compaction and lithification, which is closely related to the thickness of the sediments. Different shear wave velocities therefore reflect the differences in geology. Sediments of the Iška alluvial fan were eroded and transported from the surrounding carbonate hills in Late Pleistocene. Therefore gravel and some fine-grained sediments are characteristic for the Iška alluvial fan, whereas this is not the case for the rest of the Ljubljana Moor basin. Ljubljana Moor basin is represented mainly by lacustrine, marsh (peat and silty-clay), and to smaller extent by fluvial sediments. The differences in the obtained relationships are also a consequence of uneven borehole distribution across the Ljubljana Moor basin and a low number of boreholes in the central-Eastern part, where the basin is the deepest.

Table 1 shows the obtained $a$ and $b$ parameters for several sedimentary basins across the world, where microtremor measurements were conducted for mapping the thickness.

It is possible to notice a similarity and parallelism between most of the lines (in the log-log diagram) that represent the frequency-thickness relationships (Fig. 12), but the relations obtained in Lucerne, Switzerland (Poggi et al., 2012), Bam, Iran (Motamed et al., 2006) and Banni, India (Sant et al., 2017) deviate significantly. The comparison of parameters $a$ and $b$ 


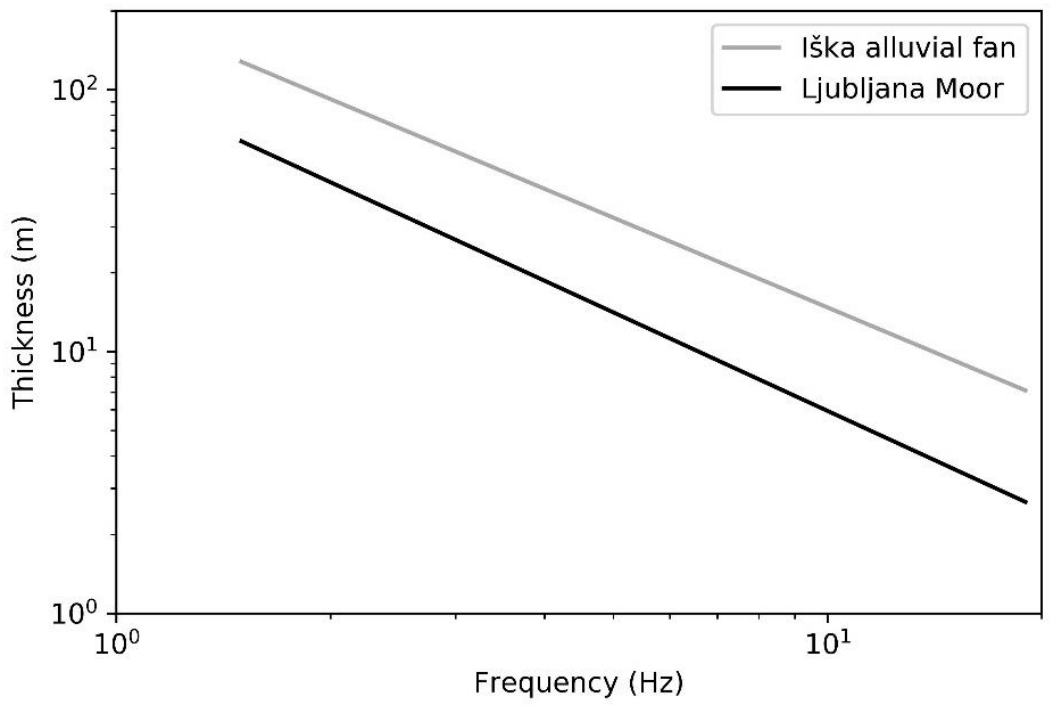

Fig. 11 Comparison between the obtained frequency-thickness relationships for the Iška alluvial fan and the Ljubljana Moor basin.

Table 1 Values of parameters $a$ and $b$ for various sedimentary basins across the world.

\begin{tabular}{llcl}
\hline Author & Sedimentary basin & $a$ & $b$ \\
\hline Ibs-von Seht and Wohlenberg (1999) & Lower-Rhine West, Germany & 96 & -1.388 \\
Delgado et al. (2000a) & Segura river valley, Spain & 55.11 & -1.256 \\
Parolai et al. (2002) & Cologne, Germany & 108 & -1.551 \\
Hinzen et al. (2004) & Lower-Rhine East, Germany & 137 & -1.19 \\
Garcia-Jerez et al. (2006) & Zafarraya Basin, Spain & 194.6 & -1.14 \\
Motamed et al. (2006) & Bam, Iran & 135.19 & $-1-979$ \\
Gosar and Lenart (2010) & Ljubljana Moor, Slovenia & 105.53 & -1.25 \\
Mascandolla et al. (2019) & Po Plain, Italy & 98 & -1.17 \\
Poggi et al. (2012) & Lucerne, Switzerland & 158.54 & -2.45 \\
D'Amico et al. (2008) & Florence, Italy & 140 & -1.172 \\
Birgören et al. (2009) & Istanbul, Turkey & 150.99 & -1.1531 \\
Del'Monaco et al (2013) & L'Aquila, Italy & 53.461 & -1.01 \\
Dinesh et al. (2010) & Bangalore, India & 58.3 & -0.95 \\
Maresca and Berrino (2016) & Volturara Irpina, Italy & 129 & -1.38 \\
Özalaybey et al. (2011) & Izmit Bay, Turkey & 141 & -1.27 \\
Paudyal et al. (2013) & Kathmandu Basin, Nepal & 146.01 & -1.2079 \\
Sukumaran et al. (2011) & Narmada Valley, India & 102.1 & -1.47 \\
Joshi et al. (2018) & Aravalli, India & 56.8 & -1 \\
Sant et al. (2017) & Banni Plains, India & 110.18 & -1.97 \\
Liang et al. (2018) & Pearl River Delta, China & 55 & -1.02 \\
Pugin et al. (2013) & Ottawa, Canada & 64.98 & -1.198 \\
This study & Iška alluvial fan, Slovenia & 202.97 & -1.139 \\
\hline
\end{tabular}

therefore reveals in general a small variation of $b$ values, and a rather large range of $a$ values, which again implies that the parameter $a$ is characteristic for certain areas. The line representing frequency- thickness relationship for the Iška alluvial fan almost coincides with the one for Zafarraya Basin, Spain (Garcia-Jerez et al., 2006), despite having a different geological setting. 

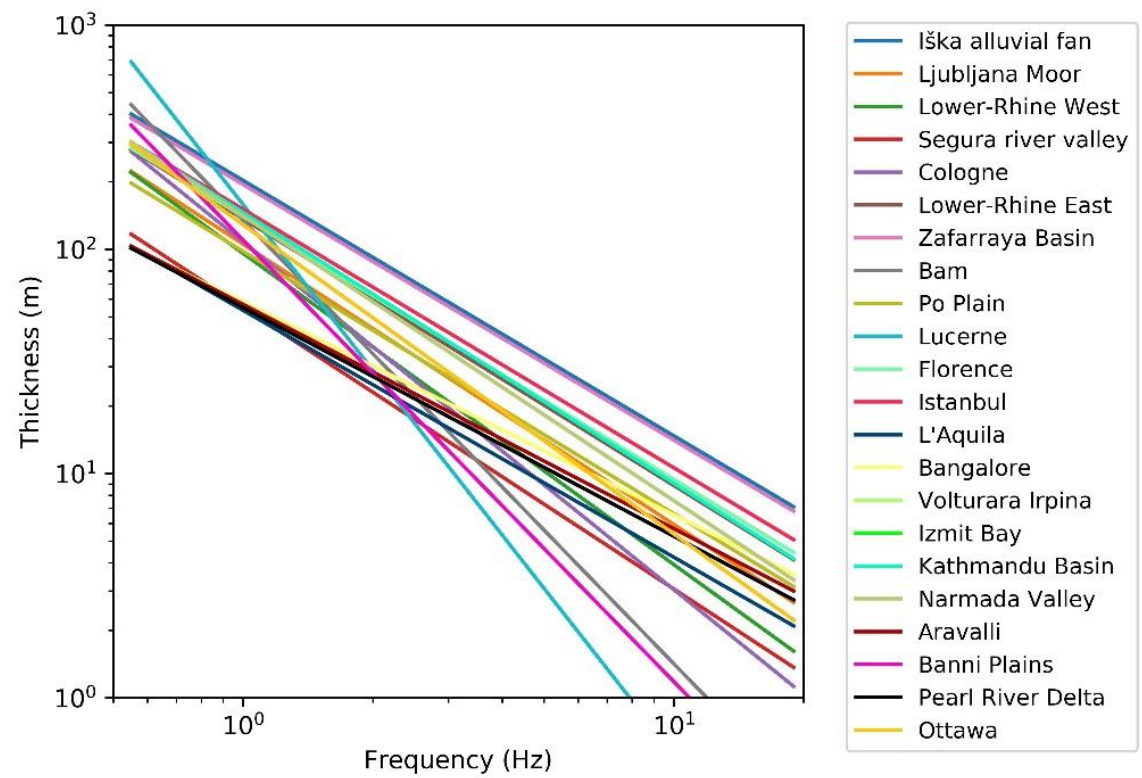

Fig. 12 Log-log diagram of frequency-thickness relationships for various sedimentary basins across the world.

\section{CONCLUSIONS}

The research carried out in the Iška alluvial fan proved the applicability of the microtremors method for mapping the thickness of sediments in sedimentary basins, for which the impedance contrast between unconsolidated sediments and the bedrock is sufficient, and as long as the influence of $3 \mathrm{D}$ effects or lateral heterogeneity in sediment composition is not a decisive factor. Due to a certain level of uncertainty of the input data, a large number of bedrock depth data, from boreholes or applied geophysical investigations, is needed for reliable frequencythickness relationship. The level of determination for the obtained relation is relatively good, and the borehole depths are in good agreement with the obtained thicknesses. Comparison of the both parameters of the frequency-thickness relationship implies that the parameter $a$ is characteristic for certain sedimentary basins, whereas the variability of parameter $b$ is relatively low.

The constructed maps of the Quaternary sediment thickness and of the Pre-Quaternary topography will improve the knowledge about the subsurface geometry of the sedimentary basement, and will contribute to more accurate hydrogeological models. Since the Iška alluvial fan represents an important source for water supply, such models are crucial for further exploitations and for protection of ground water from pollution. Therefore, the area was selected for a pilot project aimed to prepare the geological database system and the hydrogeological map in the scale 1: 25.000 (Lapanje et al., 2014).

Maps of resonance frequencies and HVSR peak amplitudes will also find use in evaluating the influence of unconsolidated sediments on seismic ground motion and possible sediments-structure resonance effects. They could be used for seismic microzonation and for spatial planning purposes. The measured resonance frequencies could therefore be used as a complementary data to the average $S$-wave velocities in the upper $30 \mathrm{~m}\left(\mathrm{~V}_{\mathrm{s}, 30}\right)$ and for the calibration of shear wave velocity profiles $\left(\mathrm{V}_{\mathrm{s}}\right)$. Although a consensus whether this is accurate has not been reached yet, according to SESAME (2004) HVSR peak amplitudes present the lower bound of seismic ground motion amplification. A relatively narrow area of lower HVSR amplitudes implies a lower impedance contrast, which could be attributed to a more fractured bedrock due to the Mišji Dol fault, whose branch crosses the area.

A proposal for further research on the Iška alluvial fan includes the use of geophysical MASW method to reveal the S-wave velocity distribution and to additionally evaluate the obtained frequencythickness relationship.

\section{ACKNOWLEDGMENTS}

The study was realized with the support of the research program P1-0011 financed by the Slovenian Research Agency.

\section{REFERENCES}

ARSO: 2015, Digital elevation model of Slovenia - $1 \mathrm{~m}$ resolution. Slovenian Environment Agency. Ljubljana.

Birgören, G., Özel, O. and Siyahi, B.: 2009, Bedrock depth mapping of the coast south of Istanbul: Comparison of analytical and experimental analyses. T. J. Earth Sci., 18, No. 2, 315-329. DOI: 10.3906/yer-0712-3 
Bonnefoy-Claudet, S., Köhler, A., Cornou, C., Wathelet, M. and Bard, P.Y.: 2008, Effects of love waves on microtremor H/V ratio. Bull. Seismol. Soc. Am., 98, No. 1, 288-300. DOI: 10.1785/0120070063

Buser, S.: 1969, Geological map of SFRJ. L 33-76, Ribnica [Map]. 1:100.000. Federal Geological Survey, Belgrade, (in Slovenian).

Castellaro, S., Mulargia, F. and Bianconi, L.: 2005, Passive seismic stratigraphy: A new efficient, fast and economic technique. Geologia Tecnica e Ambientale, 3, 76-102.

Castellaro, S. and Mulargia, F.: 2009, The effect of velocity inversions on H/V. Pure Appl. Geophys., 166, No. 4, 567-592. DOI: 10.1007/s00024-009-0474-5

D'Amico, V., Picozzi, M., Baliva, F. and Albarello, D.: 2008, Ambient noise measurements for preliminary site-effects characterisation in the urban area of Florence. Bull. Seismol. Soc. Am., 98, No. 3, 1373 1388. DOI: $10.1785 / 0120070231$

Del'Monaco, F., Tallini, M., De Rose, C. and Durante, F.: 2013, HVNSR survey in historical downtown L'Aquila (central Italy): Site resonance properties vs. subsoil model. Eng. Geol., 158, 34-47. DOI: 10.1016/j.enggeo.2013.03.008

Delgado, J., Lòpez Casado, C., Estèvez, A., Giner, J., Cuenca, A. and Molina, S.: 2000a, Mapping soft soils in the Segura river valley (SE Spain): a case study of microtremors as an exploration tool. J. Appl. Geophys., 45, No. 1, 19-32. DOI: 10.1016/S0926-9851(00)00016-1

Delgado, J., Lopez Casado, C., Giner, J., Estevez, A., Cuenca, A. and Molina, S.: 2000b, Microtremors as a geophysical exploration tool: Applications and limitations. Pure Appl. Geophys., 157, 1445-1462. DOI: $10.1007 /$ PL00001128

Dinesh, B.V., Nair, G.J., Prasad, A.G.V., Nakkeeran, P.V. and Radhakrishna, M.C.: 2010, Estimation of sedimentary layer shear wave velocity using microtremor $\mathrm{H} / \mathrm{V}$ ratio measurements for Bangalore city. Soil Dyn. Earthq. Eng., 30, No. 11, 1377-1382.

DOI: $10.1016 /$ j.soildyn.2010.06.012

Field, E. and Jacob, K.: 1993, The theoretical response of sedimentary layers to ambient seismic noise. Geophys. Res. Lett., 20, No. 24, 2925-2928. DOI: $10.1029 / 93$ GL03054

Garcia-Jerez, A., Luzon, F., Navarro, M. and Perez Ruiz, A.: 2006, Characterization of the sedimentary cover of the Zafarraya basin, southern Spain, by means of ambient noise. Bull. Seismol. Soc. Am., 96, No. 3, 957-967. DOI: $10.1785 / 0120050061$

Gosar, A. and Lenart, A. 2010: Mapping the thickness of sediments in the Ljubljana Moor basin (Slovenia) using microtremors. Bull. Earthq. Eng., 8, No. 3, 501518. DOI: 10.1007/s10518-009-9115-8

Gosar, A. and Ravnik, D.: 2007, Applied Geophysics. Faculty of Natural Sciences and Engineering, Ljubljana, 218 pp, (in Slovenian).

Guégen, P., Cornou, C., Garambois, S. and Banton, J.: 2007, On the limitation of the $H / \mathrm{V}$ spectral ratio using seismic noise as an exploration tool: application to the Grenoble valley (France), a small apex ratio basin. Pure Appl. Geophys., 164, 115-134. DOI: 10.1007/s00024-006-0151-x

Haghshenas, E., Bard, P.Y. and Theodulidis, N.: 2008, Empirical evaluation of microtremor $\mathrm{H} / \mathrm{V}$ spectral ratio. Bull. Earthq. Eng., 6, 75-108. DOI: $10.1007 / \mathrm{s} 10518-007-9058-\mathrm{x}$
Hinzen, K.G., Scherbau, M,F. and Weber, B.: 2004, On the resolution of $\mathrm{H} / \mathrm{V}$ measurements to determine sediment thickness, a case study across a normal fault in the lower Rhine embayment, Germany. J. Earthq. Eng., 8, No. 6, 909-926. DOI: $10.1142 / \mathrm{S} 136324690400178 \mathrm{X}$

Horvat, A., Brenčič, M., Skaberne, D. and Bračič-Železnik, B.: 2013, Estimating the rate of subsidence of the Iška alluvial fan are, Ljubljana Moor in Late Pleistocene. In: Rožič, B. (editor): 21.st Meeting of Slovenian Geologists, Ljubljana, 2013. Treatises, reports. Ljubljana: University of Ljubljana, Faculty of Natural Sciences and Engineering, Department of Geology, 43-46, (in Slovenian).

Ibs-Von Seht, M. and Wohlenberg, J.: 1999, Microtremor measurements used to map thickness of soft sediments. Bull. Seismol. Soc. Am., 89, No. 1, 250259.

Joshi, A.U., Sant, A.D., Parvez, A.I., Rangarajan, G., Limaye, A.M., Mukherjee, S., Charola, M.J., Bhatt, M.N. and Mistry, S.P.: 2018, Subsurface profiling of granite pluton using microtremor method southern Aravalli, Gujarat, India. Int. J. Earth Sci., 107, No. 1, 191-201. DOI: 10.1007/s00531-017-1482-9

Lachet, C. and Bard, P.Y.: 1994, Numerical and theoretical investigations on the possibilities and limitations of Nakamura's technique. J. Phys. Earth, 42, 377-397. DOI: 10.4294/jpe1952.42.377

Lapanje, A., Meglič, P., Mali, N., Jež, J., Novak, M., Jamšek Rupnik, P., Atanackov, J., Celarc, B., Urbanc, J. and Prestor, J.: 2014, Making of the methodology and the pilot input of a hydrogeological map: Interpreter of the hydrogeological map of the Iška alluvial fan pilot area, Geological Survey of Slovenia, Ljubljana, 49 pp., (in Slovenian).

Le Roux, O., Cornou, C., Jongmans, D. and Schwartz, S.: 2012, 1-D and 2-D resonances in an Alpine valley identified from ambient noise measurements and 3-D modelling. Geophys. J. Int., 191, 579-590. DOI: 10.1111/j.1365-246X.2012.05635.X

Lermo, J. and Chavez Garcia, F.J.: 1994, Are microtremors useful in site response evaluation? Bull. Seismol. Soc. Am., 84, No. 5, 1350-1364.

Liang, D., Gan, F., Zhang, W. and Jia, L.: 2018, The application of HVSR method in detecting sediment thickness in karst collapse area of Pearl River Delta, China. Environ. Earth Sci., 77, 259-268. DOI: $10.1007 / \mathrm{s} 12665-018-7439-\mathrm{x}$

Macau, A., Benjumea, B., Gaba, A., Figueras, S. and Vila, M.: 2015, The effect of shallow Quaternary deposits on the shape of the H/V spectral ratio. Surv. Geophys., 35, 185-208. DOI: 10.1007/s10712-014-9305-z

Maresca, R. and Berrino, G.: 2016, Investigation of the buried structure of the Volturara Irpina Basin (southern Italy) by microtremor and gravimetric data. J. Appl. Geophys., 128, 96-108. DOI: 10.1016/j.jappgeo.2016.03.010

Mascandolla, C., Massa, M., Barani, S., Albarello, D., Lovati, S., Martelli, S. and Poggi, V.: 2019, Mapping the seismic bedrock of the Po Plain (Italy) through ambient-vibration monitoring. Bull. Seismol. Soc. Am., 109, No. 1, 164-177. DOI: 10.1785/0120180193

Mencin, E.: 2015, Application of high resolution seismic reflection method for investigations of the depth structure of the Iška alluvial fan, Ljubljansko barje basin, central Slovenia. Faculty of Natural Sciences and Engineering, Ljubljana, 96 pp., (in Slovenian). 
Moho: 2018, Tromino, Portable ultra - light acquisition system for seismic noise and vibrations. User's manual, MoHo,Venice, 148 pp.

Molnar, S., Cassidy, J.F., Castellaro, S., Cornou, C., Crow, H., Hunter, J.A., Matsushima, S., Sanchez Sesma, F.J. and Yong, A.: 2018, Application of microtremor horizontal-to-vertical spectral ratio (MHVSR) analysis for site characterization: State of the art. Surv. Geophys., 39, 613-631.

DOI: $10.1007 / \mathrm{s} 10712-018-9464-4$

Motamed, R., Ghalandarzedah, A., Tawhata, I. and Tabatabaei, S.H.: 2007, Seismic microzonation and damage assessment of Bam city, Southeastern Iran. J. Earthq. Eng., 11, 110-132.

DOI: $10.1080 / 13632460601123164$

Özalaybey, S., Zor, E., Ergintav, S. and Tapirdamaz, M.C. 2011, Investigation of 3-D basin structures in the Izmit Bay area (Turkey) by single-station microtremor and gravimetric methods. Geophys. J. Int., 186, No. 2, 883-894. DOI: 10.1111/j.1365-246X.2011.05085.x

Parolai, S., Bormann, P. and Milkereit, C.: 2002, New relationship between Vs, thickness of sediments, and resonance frequency calculated by the $\mathrm{H} / \mathrm{V}$ ratio of seismic noise for the Cologne area (Germany). Bull. Seismol. Soc. Am., 92, No. 6, 2521-2527. DOI: $10.1785 / 0120010248$

Paudyal, Y.R., Yatabe, R., Bhandary, N.P. and Dahal, R.K.: 2013, Basement topography of the Kathmandu Basin using microtremor observation. J. Asian Earth Sci., 62, 627-637. DOI: 10.1016/j.jseaes.2012.11.011

Poggi, V., Fäh, D., Burjanek, J. and Giardini, D.: 2012, The use of Rayleigh wave ellipticity for site-specific hazard assessment and microzonation: application to the city of Lucerne, Switzerland. Geophys. J. Int., 188, 1154-1172. DOI: 10.1111/j.1365-246X.2011.05305.x

Pugin, A.J.M., Brewer, K., Cartwright, T., Pullan, S.E., Perret, D., Crow, H.L. and Hunter, J.A.: 2013, Near surface S-wave seismic reflection profiling - new approaches and insights. First Break EAGE, 31, No. 2, 49-60. DOI: 10.3997/1365-2397.20130 05

Sant, D., Parvez, A.I., Rangarajan, G., Patel, S.J., Bhatt, M.N. and Sanoop Salam, T.A.: 2017, Subsurface profiling along Banni Plains and bounding faults, Kachchh, Western India using microtremor method. J. Asian Earth Sci., 146, 326-336. DOI: $10.1016 /$ j.jseaes.2017.06.002

SESAME: 2004, Guidelines for the implementation of the $\mathrm{H} / \mathrm{V}$ spectral ratio technique on ambient vibrations: measurements, processing, and interpretation. European research project, SESAME, $63 \mathrm{pp}$.

Stanko, D., Markušić, S., Gazdek, M., Sanković, V., Slukan, I. and Ivančić, I.: 2019, Assessment of the seismic site amplification in the city of Ivanec (NW part of Croatia) using the microtremor HVSR method and equivalent-linear site response analysis. Geosciences, 9, No. 7, 312. DOI: 10.3390/geosciences 9070312

Sukumaran, P., Parvez, I.A., Sant, A.D., Rangarajan, D. and Krishnan, K.: 2011, Profiling of late Tertiary-early Quaternary surface in the lower reaches of Narmada valley using microtremors. J. Asian Earth Sci., 41, No. 3, 325-334. DOI: 10.1016/j.jseaes.2011.02.011

Uebayashi, H., Kawabe, H. and Kamae, K.: 2012, Reproduction of microseism $\mathrm{H} / \mathrm{V}$ spectral features using a three-dimensional complex topographical model of the sediment-bedrock interface in the Osaka sedimentary basin. Geophys. J. Int., 189, 1060-1074. DOI: 10.1111/j.1365-246X.2012.05408.x 